\title{
Vascular endothelial growth factor pathway
}

\author{
Michael L. Maitland ${ }^{\mathrm{a}}$, Xing Jian Lou ${ }^{\mathrm{c}}$, Jacqueline Ramirez ${ }^{\mathrm{a}}$, Apurva A. Desai $^{\mathrm{a}}$, Dorit S. \\ Berlin $^{\mathrm{c}}$, Howard L. McLeod ${ }^{\mathrm{b}}$, Ralph R. Weichselbaum ${ }^{\mathrm{a}}$, Mark J. Ratain ${ }^{\mathrm{a}}$, Russ B. Altman ${ }^{\mathrm{c}}$, \\ and Teri E. Klein ${ }^{c}$ \\ ${ }^{a}$ Department of Medicine, Section of Hematology/Oncology, University of Chicago, Maryland \\ Avenue, Chicago, Illinois \\ bUNC Institute for Pharmacogenomics and Individualized Therapy, University of North Carolina, \\ Chapel Hill, Kerr Hall, Chapel Hill, North Carolina \\ 'Department of Genetics, Stanford University, Pasteur Drive, Stanford, California, USA
}

\begin{abstract}
Keywords
angiogenesis; bevacizumab; genetic variation; pharmacogenetics; pharmacogenomics; PharmGKB; polymorphism; single nucleotide; vascular endothelial growth factor
\end{abstract}

\section{Description}

Agents inhibiting tumor angiogenesis have been developed as a new class of anticancer agents (reviewed in Ref. [1]). Several of these therapeutics target the vascular endothelial growth factor (VEGF) signaling pathway (reviewed in Ref. [2]). VEGF comprises several isoforms which bind to different receptors, including FLT1, KDR, and NRP1, and promote angiogenesis through activation of a kinase cascade that includes RAS and MAPK. Drugs that are known to interfere with the normal VEGF signaling pathway include bevacizumab, a monoclonal antibody; sorafenib and sunitinib, small molecule kinase inhibitors; and experimental drugs aflibercept, brivanib, cilengitide, axitinib, motesanib, and vandetanib (Fig. 1).

Bevacizumab, a monoclonal antibody targeting VEGFA, is indicated in combination with intravenous 5-fluoruracil-based chemotherapy for first-line or second-line treatment of patients with metastatic carcinoma of the colon or rectum, and in combination with carboplatin and paclitaxel for first-line treatment of patients with unresectable, locally advanced, recurrent, or metastatic nonsquamous, nonsmall cell lung cancer. Bevacizumab is also indicated in combination with paclitaxel for treatment of patients who have not received chemotherapy for metastatic HER2-negative breast cancer and for glioblastoma, as a single agent for patients with progressive disease following prior therapy [Avastin (bevacizumab) drug label: http://www.accessdata.fda.gov/drugsatfda_docs/label/2009/125085s0169lbl.pdf; retrieved 27 July 2009].

Sorafenib and sunitinib are small molecule kinase inhibitors [3-5]. They have overlapping activity but differing potency for inhibition of VEGFR1 (FLT1) and VEGFR2 (KDR), and sorafenib has high potency inhibition of Raf-1 (RAF1) and p38 MAP kinase (MAPK).

Sunitinib has higher potency inhibition for kinases not depicted here. Sorafenib is indicated

\footnotetext{
(C) 2010 Wolters Kluwer Health | Lippincott Williams \& Wilkins

Correspondence to Dr Teri E. Klein, PhD, Department of Genetics, Stanford University, 300 Pasteur Drive, L-301, Stanford, CA 94305-5120, USA, Tel: + 1650725 0659; fax: + 1650725 3863; feedback@pharmgkb.org.
} 
for the treatment of unresectable hepatocellular carcinoma and advanced renal cell carcinoma [Nexavar (sorafenib) drug label:

http://www.fda.gov/cder/foi/label/2007/021923s004s005s006s007lbl.pdf; retrieved 7 May 2009]. Sunitinib is indicated for the treatment of gastrointestinal stromal tumor after disease progression or intolerance to imatinib mesylate and for advanced renal cell carcinoma [Sutent (sunitinib) drug label: http://www.fda.gov/cder/foi/label/2007/021968s002s003s004s005s006lbl.pdf; retrieved May 7, 2009]. Brivanib, cilengitide, axitinib, motesanib, and vandetanib are experimental drugs influencing the angiogenesis pathway as depicted in Fig. 1 [6-11].

Recently, an association was found between VEGFA genotype and treatment outcome in a trial of paclitaxel compared with paclitaxel plus bevacizumab to treat metastatic breast cancer [12]. The AA genotype of VEGF: - 2578C > A (rs699947), a promoter polymorphism, was associated with superior median overall survival in patients receiving both paclitaxel and bevacizumab. Patients in the combination arm who carried the A allele of VEGF: - 1154G > A (rs1570360) also showed superior median overall survival. These results will require confirmation to support a role for $V E G F A$ polymorphisms in affecting clinical outcome following bevacizumab treatment for metastatic breast cancer.

Several studies have investigated variants in angiogenesis pathway genes for association with disease risk. Studies focusing on VEGFA have produced conflicting results: Schneider et al. [13] reported that the A allele of $V E G F A$ : $-2578 \mathrm{C}>\mathrm{A}(\mathrm{rs} 1547651)$ and the $\mathrm{C}$ allele of VEGFA: - 1498T > C (rs833061) are associated with increased breast cancer risk. Lu et al. [14] found that the $-460 \mathrm{C}$ (rs833061) and +405G (rs2010963) VEGFA alleles were significantly associated with reduced overall survival after diagnosis of breast cancer, and that the $-460 \mathrm{~T} /+405 \mathrm{C} /+936 \mathrm{C}$ (rs3025039) haplotype was significantly associated with increased overall survival. A large-scale evaluation of single nucleotide polymorphisms (SNPs) identified four SNPs in the VEGFA promoter region [the TT genotype of VEGFA:Ex1-73C > T (rs25648) the AA genotype of VEGFA: - 15648A > C (rs833052), the TT genotype of VEGFA: - 9228G > T (rs1109324), and the TT genotype of VEGFA: 8339A > T (rs1547651)] that were associated with increased bladder cancer risk and one intronic SNP associated with reduced bladder cancer risk [the CT genotype of $V E G F A$ :IVS2+1378C > T (rs3024994)] [15]. The CC genotype of VEGFA: - 1498T > C (rs833061) has been shown to be associated with decreased risk of bone metastases in breast cancer patients [16]. Other research has shown no association between VEGFA variants and risk of developing breast cancer [17-19], colorectal cancer [20], prostate cancer [21], or non-small cell lung cancer [22].

Selected polymorphisms in other VEGF pathway genes, including $K D R, F L T 1, N O S 3$, and $N R P 1$ were not associated with breast cancer risk [13]. The same study also found that the NOS3: - 786TT (rs2070744) genotype is significantly associated with greater likelihood of invasive breast cancer, and that the NOS3: 894GG (rs1799983) genotype is associated with increased likelihood of having metastatic disease. Further research is necessary to clarify the role of angiogenesis pathway gene variants in disease etiology and drug treatment outcome.

As a guide to future investigation of potential mechanisms of inter-individual variability of efficacy and toxicity, multiple signaling molecules and a simplified depiction of their interactions are diagrammed. While these signaling pathways are active in multiple cell types, the diagram and the supporting data are limited to the endothelial cell, as endothelial cells are thought to be the primary target of these agents in the treatment of cancer. Many more interactions and molecules have been described as important to angiogenesis and to VEGF signaling. This diagram, however, limits its scope to the molecules inhibited by the 
depicted agents and the immediately interacting signaling molecules shown primarily in mammals or mammalian cell lines.

A clickable version of the VEGF pathway diagram and an Excel spreadsheet containing references for the pathway interactions depicted in Fig. 1 may be accessed at the Pharmacogenomics Knowledge Base (PharmGKB) at http://www.pharmgkb.org/do/serve?objId=PA2032\&objCls=Pathway.

\section{Acknowledgments}

PharmGKB is supported by the NIH/NIGMS Pharmacogenetics Research Network and Database (UO1GM61374).

\section{References}

1. Fujita Y, Abe R, Shimizu H. Clinical approaches toward tumor angiogenesis: past, present and future. Curr Pharm Des. 2008; 14:3820-3834. [PubMed: 19128235]

2. Tonra JR, Hicklin DJ. Targeting the vascular endothelial growth factor pathway in the treatment of human malignancy. Immunol Invest. 2007; 36:3-23. [PubMed: 17190647]

3. Wilhelm SM, Carter C, Tang L, Wilkie D, McNabola A, Rong H, et al. BAY 43-9006 exhibits broad spectrum oral antitumor activity and targets the RAF/MEK/ERK pathway and receptor tyrosine kinases involved in tumor progression and angiogenesis. Cancer Res. 2004; 64:7099-7109. [PubMed: 15466206]

4. Mendel DB, Laird AD, Xin X, Louie SG, Christensen JG, Li G, et al. In vivo antitumor activity of SU11248, a novel tyrosine kinase inhibitor targeting vascular endothelial growth factor and plateletderived growth factor receptors: determination of a pharmacokinetic/pharmacodynamic relationship. Clin Cancer Res. 2003; 9:327-337. [PubMed: 12538485]

5. Sun L, Liang C, Shirazian S, Zhou Y, Miller T, Cui J, et al. Discovery of 5-[5-fluoro-2-oxo-1,2dihydroindol-(3Z)-ylidenemethyl]-2,4- dimethyl-1H-pyrrole- 3-carboxylic acid (2diethylaminoethyl)amide, a novel tyrosine kinase inhibitor targeting vascular endothelial and platelet-derived growth factor receptor tyrosine kinase. J Med Chem. 2003; 46:1116-1119. [PubMed: 12646019]

6. Cai ZW, Zhang Y, Borzilleri RM, Qian L, Barbosa S, Wei D, et al. Discovery of brivanib alaninate ((S)-((R)-1-(4-(4-fluoro-2-methyl-1H-indol-5-yloxy)-5-methylpyrrolo[2,1-f][1,2,4] triazin-6yloxy)propan-2-yl)2-aminopropanoate), a novel prodrug of dual vascular endothelial growth factor receptor-2 and fibroblast growth factor receptor-1 kinase inhibitor (BMS-540215). J Med Chem. 2008; 51:1976-1980. [PubMed: 18288793]

7. Huynh H, Ngo VC, Fargnoli J, Ayers M, Soo KC, Koong HN, et al. Brivanib alaninate, a dual inhibitor of vascular endothelial growth factor receptor and fibroblast growth factor receptor tyrosine kinases, induces growth inhibition in mouse models of human hepatocellular carcinoma. Clin Cancer Res. 2008; 14:6146-6153. [PubMed: 18829493]

8. Goodman SL, Holzemann G, Sulyok GA, Kessler H. Nanomolar small molecule inhibitors for alphav (beta)6, alphav (beta)5, and alphav (beta)3 integrins. J Med Chem. 2002; 45:1045-1051. [PubMed: 11855984]

9. Rugo HS, Herbst RS, Liu G, Park JW, Kies MS, Steinfeldt HM, et al. Phase I trial of the oral antiangiogenesis agent AG-013736 in patients with advanced solid tumors: pharmacokinetic and clinical results. J Clin Oncol. 2005; 23:5474-5483. [PubMed: 16027439]

10. Polverino A, Coxon A, Starnes C, Diaz Z, DeMelfi T, Wang L, et al. AMG706, an oral, multikinase inhibitor that selectively targets vascular endothelial growth factor, platelet-derived growth factor, and kit receptors, potently inhibits angiogenesis and induces regression in tumor xenografts. Cancer Res. 2006; 66:8715-8721. [PubMed: 16951187]

11. Wedge SR, Ogilvie DJ, Dukes M, Kendrew J, Chester R, Jackson JA, et al. ZD6474 inhibits vascular endothelial growth factor signaling, angiogenesis, and tumor growth following oral administration. Cancer Res. 2002; 62:4645-4655. [PubMed: 12183421]

12. Schneider BP, Wang M, Radovich M, Sledge GW, Badve S, Thor A, et al. Association of vascular endothelial growth factor and vascular endothelial growth factor receptor-2 genetic 
polymorphisms with outcome in a trial of paclitaxel compared with paclitaxel plus bevacizumab in advanced breast cancer: ECOG 2100. J Clin Oncol. 2008; 26:4672-4678. [PubMed: 18824714]

13. Schneider BP, Radovich M, Sledge GW, Robarge JD, Li L, Storniolo AM, et al. Association of polymorphisms of angiogenesis genes with breast cancer. Breast Cancer Res Treat. 2008; 111:157-163. [PubMed: 17891484]

14. Lu H, Shu XO, Cui Y, Kataoka N, Wen W, Cai Q, et al. Association of genetic polymorphisms in the VEGF gene with breast cancer survival. Cancer Res. 2005; 65:5015-5019. [PubMed: 15958542]

15. Garcia-Closas M, Malats N, Real FX, Yeager M, Welch R, Silverman D, et al. Large-scale evaluation of candidate genes identifies associations between VEGF polymorphisms and bladder cancer risk. PLoS Genet. 2007; 3:e29. [PubMed: 17319747]

16. Clar H, Krippl P, Renner W, Langsenlehner T, Clar V, Windhager R, et al. Association of polymorphisms of angiogenesis genes with breast cancer. Breast Cancer Res Treat. 2009; 113:197-198. [PubMed: 18210198]

17. Langsenlehner U, Wolf G, Langsenlehner T, Gerger A, Hofmann G, Clar H, et al. Genetic polymorphisms in the vascular endothelial growth factor gene and breast cancer risk. The Austrian 'tumor of breast tissue: incidence, genetics, and environmental risk factors' Study. Breast Cancer Res Treat. 2008; 109:297-304. [PubMed: 17636397]

18. Jacobs EJ, Feigelson HS, Bain EB, Brady KA, Rodriguez C, Stevens VL, et al. Polymorphisms in the vascular endothelial growth factor gene and breast cancer in the Cancer Prevention Study II cohort. Breast Cancer Res. 2006; 8:R22. [PubMed: 16613616]

19. Jin Q, Hemminki K, Enquist K, Lenner P, Grzybowska E, Klaes R, et al. Vascular endothelial growth factor polymorphisms in relation to breast cancer development and prognosis. Clin Cancer Res. 2005; 11:3647-3653. [PubMed: 15897560]

20. Hofmann G, Langsenlehner U, Renner W, Langsenlehner T, Yazdani-Biuki B, Clar H, et al. Common single nucleotide polymorphisms in the vascular endothelial growth factor gene and colorectal cancer risk. J Cancer Res Clin Oncol. 2008; 134:591-595. [PubMed: 17938959]

21. Langsenlehner T, Langsenlehner U, Renner W, Krippl P, Mayer R, Wascher TC, et al. Single nucleotide polymorphisms and haplotypes in the gene for vascular endothelial growth factor and risk of prostate cancer. Eur J Cancer. 2008; 44:1572-1576. [PubMed: 18514506]

22. Zhai R, Liu G, Zhou W, Su L, Heist RS, Lynch TJ, et al. Vascular endothelial growth factor genotypes, haplotypes, gender, and the risk of non-small cell lung cancer. Clin Cancer Res. 2008; 14:612-617. [PubMed: 18223238] 


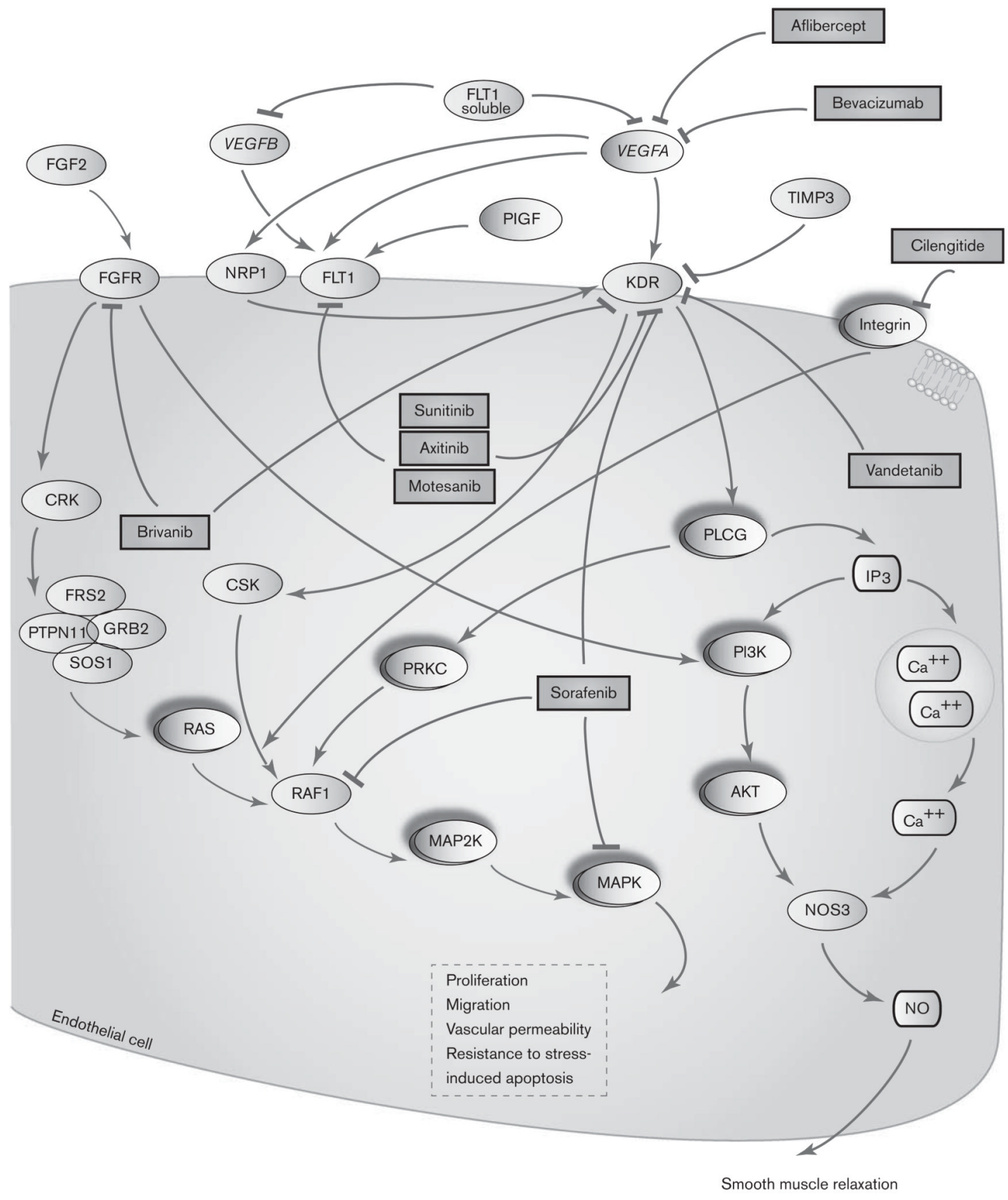

Fig. 1.

Representation of genes of the vascular endothelial growth factor (VEGF) signaling pathway and the sites at which bevacizumab, sorafenib, sunitinib, brivanib, and cilengitide are known to act. 